\title{
Research on Improvement Plan of Low-voltage Area Line Loss Calculation RUAN Bo ${ }^{1}$, LI Yu ${ }^{2}$, ZHANG Bu-han ${ }^{2}$, SU Fu-wen ${ }^{2}$

\author{
(1. Economy \& Technology Research Institute of State Grid Hubei Electric Power Company, Wuhan Hubei \\ 430077, China; \\ 2. Huazhong University of Science and Technology, Wuhan Hubei 430074, China)
}

\begin{abstract}
(Abstract) With the development of smart distribution grid, metering devices for low voltage distribution network is getting better and better, which lays the foundation for the accurate calculation of theoretical line loss. Firstly, this article points out existing problem of commonly used calculation methods--equivalent resistance method for low-voltage area theoretical line loss. Secondly, under the premise of adequate configuration of the metering devices, this article puts forward two kinds of theoretical calculation methods of low voltage area line loss, which are improved equivalent resistance method by using the head end of three phase current and the improved back/forward sweep method based on equivalent resistance. At last, the proposed plan is applied to the actual low voltage area, which verifies the feasibility of the plan.
\end{abstract}

Key Words: line loss; low-voltage area; equivalent resistance method; three-phase unbalance;

\section{Introduction}

Line loss rate is not only the important reference index for production and operation of power company, but also the comprehensive reflection of planning, design, production, operation, management of power system and enterprise economic level ${ }^{(1,2)}$.

Considering the present situation of line loss management, many power supply companies put forward a lot of control measures for line losses reduction. ${ }^{(3-6)}$ The line loss management of low-voltage area $\left.{ }^{(7-8)}\right)$ is difficult due to complicated structure and incomplete data of low-voltage area.

\section{Summary of line loss management}

Line loss means the power energy loss caused by the electricity on the distribution line transforms into thermal energy, management line loss and statistical line loss. The relationship among three losses is shown in formula (1-1); Line loss rate is the percentage of power loss divided by power supply. Generally the line loss rate can be classified into actual line loss rate and theoretical line loss rate, the calculation methods are shown in formula (1-2) and (1-3) ${ }^{(9-10)}$.

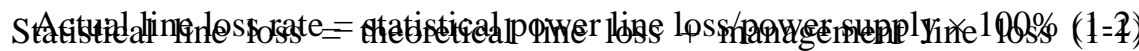

Theoretical line loss $=$ theoretical line loss of power/power supply $\times 100 \%(1-3)$

Statistical line loss is the difference between actual power supply and powers sales calculated by residual method in accordance with the power meter reading; Management line loss is equal to the difference between statistical line loss and theoretical line loss, including line loss caused by lots of uncertain factors, so the management line loss also called unknown loss.

\section{Existing calculation method for low-voltage area}

The low-voltage distribution network of $0.4 \mathrm{kV}$ and below has two characteristics: First, the way and structure of power supply is complex, mainly three-phase four-line and single-phase two-line; Second, the power load varies greatly, and the meter and device are not complete so that the complete operating records and materials are lacked. So it is tough to accurately calculate the theoretical line loss of low-voltage distribution network. ${ }^{(12)}$.

\section{a) Assumptions of existing calculation method for low-voltage area}

(1) Assuming that the load power factor of user side is equal to the load power factor of head end in the station area.

(2) Assuming that the load curve of user side is similar to the load curve of head end in the station area.

(3) Assuming that the voltage of each node is equal to the voltage of head end in distribution feeder, ignoring the influence of the line voltage drop on the line loss. 


\section{b) Existing calculation method of equivalent resistance}

The basic idea of equivalent resistance method: the power energy loss caused by each branch current flows through the resistance is equal to the power energy loss caused by the outlet current flows through the equivalent resistance. The formula for calculating the equivalent resistance is as follows:

$$
R_{e q}=\frac{\sum_{j=1}^{m_{j}} N_{j} A_{j, \Sigma}{ }^{2} R_{j}}{\left(\sum_{i=1}^{m} A_{i}\right)^{2}}(\Omega)
$$

In the formula (2-1), $A_{j, \Sigma}$ is the sum of power meter reading of low-voltage user in a certain line, $\mathrm{kWh} ; A_{i}$ is the sum of power meter reading of all users in the station area, $\mathrm{kWh} ; R_{j}$ is a resistance in the calculated line, $R_{j}=r_{o j} L_{j}, \Omega ; N_{j}$ is a structure constant of the calculated line, the constant will be 6 if the line is single-phase single-wire, and the constant will be1 if the line is three-phase four-line.

\section{c) Power energy loss calculation}

The formula for calculating the power loss of the distribution network in low-voltage area is as follows:

$$
\Delta A_{k}=3 I_{T, r m s}^{2} R_{e q} T \times 10^{-3}(\mathrm{kWh})
$$

In the formula (2-2), $I_{T, r m s}$ is the root mean square value of head end current of distribution network in period T; the $T$ normally takes a day of 24 hours.

\section{d) Modified coefficient of equivalent resistance method}

Assuming that the daily active power supply and reactive power supply are respectively $A_{P}$ and $A_{Q}$, the average operating line voltage is $V_{l}$, the current records of 24 hours are $I_{t}(t=1,2, \ldots, 24)$ in the distribution line on representative day. If the $A_{P}$ and $A_{Q}$ are divided into each hour in accordance with the graph of load current, the daily active power and reactive power of distribution line outlet are:

$$
\begin{aligned}
& P_{t}=A_{P} \bullet \frac{I_{t}}{I_{\Sigma}}(\mathrm{kW}) \\
& Q_{t}=A_{Q} \bullet \frac{I_{t}}{I_{\Sigma}}(\mathrm{kVar})
\end{aligned}
$$

Therein:

$$
I_{\Sigma}=\sum_{t=1}^{24} I_{t}(\mathrm{~A})
$$

The hourly calculated current of the distribution line outlet is

$$
I_{t}^{\prime}=\frac{\sqrt{P_{t}^{2}+Q_{t}^{2}}}{\sqrt{3} V_{l}}=\frac{\sqrt{A_{P}^{2}+A_{Q}^{2}}}{\sqrt{3} V_{l} I_{\Sigma}} \bullet I_{t}(\mathrm{~A})
$$

So the modified coefficient of equivalent resistance method is

$$
k=\frac{I_{t}^{\prime}}{I_{t}}=\frac{\sqrt{A_{P}^{2}+A_{Q}^{2}}}{\sqrt{3} V_{l} I_{\Sigma}}
$$

Due to the variable line loss $\Delta A_{k}$ (sum of the line loss and the copper loss of distribution network transformer) of distribution network is directly proportional to the square of load current, the modified formula of variable line loss is

$$
\Delta A_{k}^{\prime}=k^{2} \cdot \Delta A_{k}=\frac{A_{P}^{2}+A_{Q}^{2}}{3\left(V_{l} I_{\Sigma}\right)^{2}} \Delta A_{k}(\mathrm{kWh})
$$


References (11) and (16) considered the influence of unbalanced three-phase current on line loss, the value of power energy loss would be corrected by three-phase unbalance coefficient $k_{u b}$. First introducing the unbalance factor of current $\beta_{\phi}$, the formula is

$$
\beta_{\phi}=\left(I_{\phi}-I_{a v}\right) / I_{a v}
$$

Where, $I_{\phi}$ is three-phase current; $I_{a v}=\frac{1}{3}\left(I_{A}+I_{B}+I_{C}\right)(\mathrm{A})$.

If the resistance of neutral line and phase line are $R$ in three-phase four-wire line, power factors of each phase are the same, the power loss of phase line is

$$
\begin{aligned}
& \Delta P_{\varphi}=\left(\left(1+\beta_{A}\right)^{2}+\left(1+\beta_{B}\right)^{2}\right. \\
& \left.+\left(1+\beta_{C}\right)^{2}\right) I_{a v}^{2} R(\mathrm{~W})
\end{aligned}
$$

Because of $\beta_{A}+\beta_{B}+\beta_{C}=0, \Delta P_{\varphi}=\left(3+\beta_{A}^{2}+\beta_{B}^{2}+\beta_{C}^{2}\right) I_{a v}^{2} R(\mathrm{~W})$

Null line current:

$$
\begin{aligned}
& I_{N}=\left(1+\beta_{A}\right) I_{a v}+\left(1+\beta_{B}\right)\left(-\frac{1}{2}-j \frac{\sqrt{3}}{2}\right) I_{a v} \\
& +\left(1+\beta_{C}\right)\left(-\frac{1}{2}+j \frac{\sqrt{3}}{2}\right) I_{a v} \text { (A) }
\end{aligned}
$$

The loss of null line is

$$
\begin{aligned}
& \Delta P_{N}=\left(\beta_{A}-\frac{\beta_{B}}{2}-\frac{\beta_{C}}{2}\right)^{2} \\
& +\left(\frac{\sqrt{3}}{2} \beta_{C}-\frac{\sqrt{3}}{2} \beta_{B}\right)^{2} I_{a v}^{2} R(\mathrm{~W})
\end{aligned}
$$

Total losses:

$$
\begin{aligned}
& \Delta P=\Delta P_{\varphi}+\Delta P_{N}=\left(3+2\left(\beta_{A}^{2}+\beta_{B}^{2}+\beta_{C}^{2}\right)\right. \\
& \left.-\beta_{A} \beta_{B}-\beta_{B} \beta_{C}-\beta_{C} \beta_{A}\right) I_{a v}^{2} R(\mathrm{~W})
\end{aligned}
$$

The three-phase unbalance coefficient is

$$
\begin{aligned}
& K_{u b}=\frac{\Delta P_{\varphi}+\Delta P_{N}}{\Delta P_{\varphi}}= \\
& \frac{3+2\left(\beta_{A}^{2}+\beta_{B}^{2}+\beta_{C}^{2}\right)-\beta_{A} \beta_{B}-\beta_{B} \beta_{C}-\beta_{C} \beta_{A}}{3+\beta_{A}^{2}+\beta_{B}^{2}+\beta_{C}^{2}}
\end{aligned}
$$

In case of unbalanced three-phase current, the power energy loss is

$$
\Delta A_{k}^{\prime}=k_{u b} \Delta A_{k}(\mathrm{kWh})
$$

Using current correction coefficient $k$ from formula (2-3) to formula (2-7) to correct and figure out the line loss:

$$
\begin{aligned}
& \Delta A_{k}^{\prime}=k_{u b} k^{2} \cdot \Delta A_{k} \\
& =k_{u b} \frac{A_{P}^{2}+A_{Q}^{2}}{3\left(V_{a} I_{\Sigma}\right)^{2}} \Delta A_{k}(\mathrm{kWh})
\end{aligned}
$$

\section{Improvement plan of Line Loss of Low-voltage Area}

(1) In accordance with the three-phase unbalance degree $k_{u b}$, the three-phase unbalance degree of each day is a fixed value;

(2) Ignored the influence of voltage drop along wire and other factors on line loss. 


\section{a) The improved equivalent resistance method of using three-phase current of head end}

The improved equivalent resistance method of using three-phase current of head end adopts 24-hour three-phase current of station area outlet to reflect three-phase current unbalance and load fluctuation:

$$
\begin{aligned}
& \Delta A_{k}=\left(I_{a}^{2} R_{a}+I_{b}^{2} R_{b}+I_{c}^{2} R_{c}+I_{0}^{2} R_{0}\right) \\
& \times T \times 10^{-3}(\mathrm{kWh})
\end{aligned}
$$

Where, the current of null line is equal to the vector sum of three-phase current, the expression is

$$
\dot{I_{0}}=\dot{I}_{a}+\dot{I}_{b}+\dot{I}_{c}(\mathrm{~A})
$$

If the resistance value of three-phase phase line $R_{a}, R_{b}, R_{c}$ are equal to the resistance value of neutral line $R_{0}$, which are all equivalent resistance $R_{e q}$, the formula (3-1) can be simplified as:

$$
\begin{aligned}
& \Delta A_{k}=\left(I_{a}^{2}+I_{b}^{2}+I_{c}^{2}\right. \\
& \left.+\left|\dot{I}_{a}+\dot{I}_{b}+\dot{I}_{c}\right|^{2}\right) R_{\mathrm{eq}} \times T \times 10^{-3}(\mathrm{kWh})
\end{aligned}
$$

In the calculation, assuming that the phase angle differences among phase $\mathrm{A}, \mathrm{B}$ and $\mathrm{C}$, under the condition of unbalanced load, are $120^{\circ}$, so after knowing the three-phase current amplitude, the expression of $\dot{I}_{a}, \dot{I}_{b}, \dot{I}_{c}$ can be obtained, thus the value of current of null line $I_{0}$ is obtained. Equivalent resistance is obtained from formula (2-1).

Using correction coefficient from formula (3-3) to formula (3-7) to correct and figure out the line loss, the ultimate theoretical calculation result of electricity of line loss is

$$
\Delta A_{k}^{\prime}=k^{2} \cdot \Delta A_{k}=\frac{A_{P}^{2}+A_{Q}^{2}}{3\left(V_{a} I_{\Sigma}\right)^{2}} \times \Delta A_{k}(\mathrm{kWh})
$$

\section{b) The improved equivalent resistance method based on back/forward sweep.}

There are too many assumptions in the original equivalent resistance method. Great error will be made when the actual assumptions deviate from the theoretical assumptions.

\section{i. Process of back/forward sweep method}

Take the circuit as single-phase circuit for power flow calculation, all data are converted into per-unit value. The specific principles of calculation are as follows:

(1) Set the initial values of nodes voltage: $\dot{U}_{i}(c)=1 ; \mathrm{i}=1,2,3, \ldots \ldots \mathrm{n}, \mathrm{n}$ is the number of nodes; $\mathrm{c}$ is the number of cycles.

(2) Inputting the current into the node that calculated by formula (3-1)

$$
\dot{I}_{i}=A_{i}\left(1-j \tan \varphi_{i}\right) / \sqrt{3} \dot{U}_{i(\mathrm{c})} T(\text { p.u. })
$$

In the formula, $\dot{I}_{i}$ is the average current (complex number) of node; $A_{i}$ is the active electrical degree of node (user) measured in period $\mathrm{T}$, normally it is of daily active electricity, the value of $T$ is $24 ; \varphi_{i}$ is load power factor angle of node. $\dot{U}_{i(\mathrm{c})}$ is the voltage of node $\mathrm{i}$, c is number of cycle, if $c=0$, the $\dot{U}_{i(\mathrm{c})}$ is the initial voltage value before performing iteration calculation, it normally is $\mathrm{i}+\mathrm{j} 0$; during the process of back/forward sweep, voltage of each node will be varied.

(3) Calculating the current of each branch from the foot branch: figure out current $I_{i j(c)}$ ("i $\mathrm{i}$ " is the parent node) of each branch from the foot branch to each sub branch:

$$
\dot{I}_{i j(\mathrm{c})}=\frac{A_{i}\left(1-j \tan \varphi_{i}\right)}{\sqrt{3} \dot{U}_{i(\mathrm{c})} T}+\sum_{k=1}^{m} \dot{I}_{j k(\mathrm{c})}(\text { p.u. })
$$


Where, $\mathrm{m}$ is the collection of all sub-branches which are directly connected to the node $\mathrm{j}, \dot{I}_{j k(\mathrm{c})}$ is the current of corresponding branch. If the power factors of the head end of station area side and user side are same.

(4) Sweeping forward to figure out node voltage: sweeping from the first branch to following branches to figure out voltage of each node:

$$
\dot{U}_{j}(\mathrm{c}+1)=\dot{U}_{i}(\mathrm{c}+1)-\dot{I}_{i j(\mathrm{c})} Z_{i j}(\text { p.u. })
$$

Where, “j” is the parent node, "il" is the sub node, $Z_{i j}$ is the impedance between branch $\mathrm{i}$ and $\mathrm{j}$.

(5) Calculating the correction value of voltage amplitude of each load node:

$$
\Delta U_{j}(\mathrm{c}+1)=\left|\dot{U}_{i}(\mathrm{c}+1)\right|-\left|\dot{U}_{i}(\mathrm{c})\right|(\text { p.u. })
$$

(6) Calculating the maximum correction value of each node. $\left|\Delta U_{j}(\mathrm{c}+1)\right|$

(7) Convergence criteria:

$$
\max \left|\Delta U_{j}(\mathrm{c}+1)\right|<\varepsilon
$$

Where, $\varepsilon$ is the accuracy of calculation, if the maximum correction value of voltage is greater than accuracy of calculation, the cycle ends and the calculation result is obtained; if not, repeat step (2) - (7) until the requirement of (5) is met.

\section{ii. Calculation of equivalent resistance and line loss of station area}

The current of each line, power of head end and terminal end and voltage of each node can be calculated by back/forward sweep method for power flow The method can directly figure out the line loss,.Converting all values into actual value for next calculation, the expression for hourly line loss of station area is

$$
\begin{aligned}
& \Delta P=\sum_{l=1}^{m}\left[\left(P_{z j}^{2}+Q_{z j}^{2}\right) / V_{j}^{2}\right] R_{l} \\
& =\left[\left(P_{\Sigma}^{2}+Q_{\Sigma}^{2}\right) / V_{S}^{2}\right] R_{e q}(\mathrm{~kW})
\end{aligned}
$$

Where, $P_{z j}$ and $Q_{z j}$ is respectively active power and reactive power of terminal end of the "I" branch, $V_{j}$ is the voltage of terminal end node of the "I" branch, $R_{l}$ is the resistance of branch I; $P_{\Sigma}$ and $Q_{\Sigma}$ is the power of root node of outlet of station area, $V_{S}$ is the voltage of the root node of outlet of station area.According to the formula (3-6), the equivalent resistance of station area is

$$
R_{e q}=\frac{\sum_{l=1}^{m}\left[\left(P_{z j}^{2}+Q_{z j}^{2}\right) / V_{j}^{2}\right] R_{l}}{\left[\left(P_{\Sigma}^{2}+Q_{\Sigma}^{2}\right) / V_{S}^{2}\right]}(\Omega)
$$

Comparing back/forward sweep method and original method, the former considers the influence of voltage drop along the line on line loss, therefore the result is more accurate by using back/forward sweep method.Put the equivalent resistance $R_{e q}$ into the formula (3-3) which considering the influence of load fluctuation and three-phase unbalance on line loss, and obtain the line loss of distribution lines by using formula (3-4). 


\section{Case study}

\section{a) Structure and parameters of station area}

A network structure diagram of $0.4 \mathrm{kV}$ station area is shown in Fig. 2, determining the calculation sequence by There are total 15 nodes and branches and 9 users; the daily power supply is $141.12 \mathrm{kWh}$, the daily power sales is $136.59 \mathrm{kWh}$, and the daily power loss is $4.53 \mathrm{kWh}$ (including the estimated meter loss of $1.300 \mathrm{kWh}$ ), the statistic lien loss is $3.21 \%$, the power factor is 0.9 , there are two types of the wires, LGJ-25 and BLV-16. In Fig. 2, the line $l_{3,4}, l_{8,9}, l_{10,12}$ and $l_{13,15}$ are single-phase one-wire, and the rest of lines are three-phase four-wire.

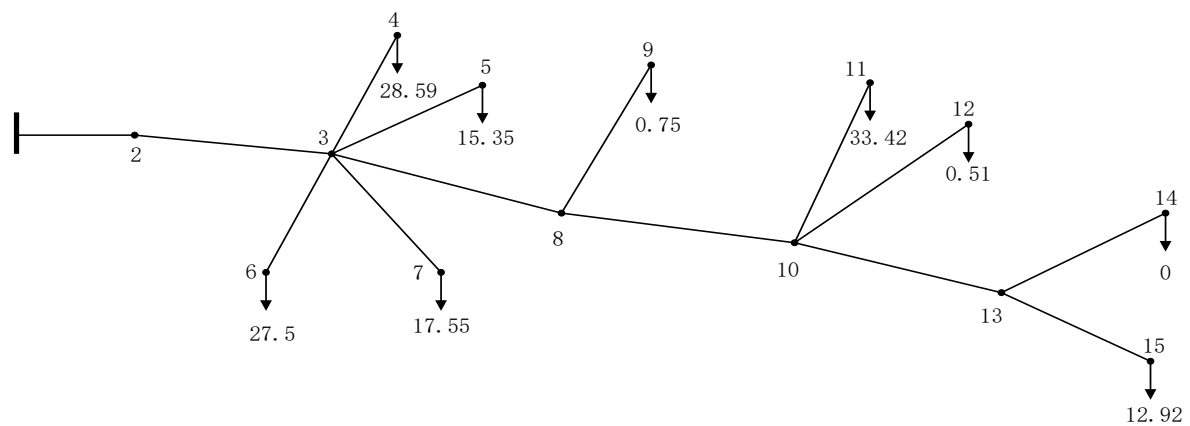

Fig. 2 Network structure diagram of the station area

\section{b) Calculation of improvement plan}

The result of theoretical line loss of the station area by applying improved method is shown in Tab. 2 .

Tab. 2 The calculation results of theoretical line loss

\begin{tabular}{|c|c|c|c|c|c|c|c|}
\hline \multicolumn{3}{|c|}{ Calculation method } & $\begin{array}{c}\text { Equivalent } \\
\text { resistance/ } \\
\Omega\end{array}$ & $\begin{array}{c}\text { Line } \\
\text { loss/kWh }\end{array}$ & $\begin{array}{c}\text { Meter } \\
\text { loss/kWh }\end{array}$ & $\begin{array}{c}\text { Total } \\
\text { loss } / \mathrm{kWh}\end{array}$ & $\begin{array}{c}\text { Line loss } \\
\text { rate }\end{array}$ \\
\hline $\begin{array}{l}\text { Original } \\
\text { method }\end{array}$ & \multicolumn{2}{|c|}{ Equivalent resistance method } & 0.155 & 1.748 & 1.300 & 3.048 & $2.16 \%$ \\
\hline \multirow{2}{*}{$\begin{array}{l}\text { Improve } \\
\text { ment } \\
\text { methods }\end{array}$} & $\begin{array}{l}\text { Metho } \\
\text { d One }\end{array}$ & $\begin{array}{l}\text { The improved equivalent } \\
\text { resistance method of } \\
\text { using three-phase current } \\
\text { of head end }\end{array}$ & 0.155 & 2.109 & 1.300 & 3.409 & $2.42 \%$ \\
\hline & $\begin{array}{l}\text { Metho } \\
\text { d Two }\end{array}$ & $\begin{array}{l}\text { The improved equivalent } \\
\text { resistance method based } \\
\text { on back/forward sweep. }\end{array}$ & 0.183 & 2.490 & 1.300 & 3.790 & $2.69 \%$ \\
\hline
\end{tabular}

The improved equivalent resistance method based on back/forward sweep needs more information, such as network structure and load power factors of each node.

\section{Conclusion}

This paper provides two improvement plan according to the equivalent resistance method based on original calculation method for line loss of low-voltage area, the improved equivalent resistance method of using three-phase current of head end and the improved equivalent resistance method based on back/forward sweep. These two improvement plans are applied to calculate the theoretical line loss of low-voltage area of $0.4 \mathrm{kV}$ power supply station, and the results are compared with the result calculated by the original method. The result shows that the effect of these two improvement plans are significant. In accordance with existing data and accuracy requirements, there are options for the calculation line loss of low voltage distribution network: if the data is complete, the improved equivalent resistance method based on back/forward sweep is selected to accurately calculate the line loss; if the data is incomplete, the improved equivalent resistance method of using three-phase 
current of head end will be considered to estimate the line loss.

\section{References}

(1) Sun Ruifeng. Power Loss Calculation Method for Distribution Network(J). Northeast Electric Power Technology, 2010, 31(2):34-36

(2) Wang Tao, Zhang Jianmin, Li Xiaoping. Calculation and Evaluation of Scheduled Loss Ratio(J). Central China Electric Power, 2003, 16(1):5-7.

(3) Zhao Jihong. The Line Loss Management of Power System in 10kV Network(J). Rural Electrification, 1999(11):39-42.

(4) Han F, Yin M, Jun L I, et al. Discussions on Related Issues of Smart Grid Development in China(J). Power System Technology, 2009, 33(15):47-53.

(5) He Jian, Ding Lvna. Development and Application of the Visual Theoretically Calculating Software for the Distribution Network's Flow Loss(J). Zhejiang Electric Power, 2002, 21(3):6-9.

(6) Tai H, Hogain E O. Behind the buzz (In My View)(J). IEEE Power \& Energy Magazine, 2009, 7(2):96-92.

(7) Lu Yang, Zhou Hongguang, Lan Caijin. Analysis of Improved Distribution Network’s Line Loss Calculation Method(J) Electrical Engineering, 2013(1):98-100.

(8) Ding Xinhai. Research on Power Loss Calculation Method for Distribution Network(D). Wuhan University of Hydraulic and Electric Engineering Wuhan University, 1997.

(9) Yang Yaojie. Study on the Manage Model of Low-voltage Public Transformer District(D). Zhengzhou University, 2004.

(10) Tan Yafeng, Li Yunlong, Sang Chuanchuan. Analysis of Line Loss Management of Urban Power Supply Bureau(J). Guangxi Electric Power, 2016(14):37-39. 